\title{
What is the role of self-esteem in adolescents with idiopathic scoliosis under a conservative treatment?
}

\author{
E D’Agata $^{1 *}$, C Pérez-Testor ${ }^{2}$, S Negrini ${ }^{3,4}$, M Rigo ${ }^{5}$ \\ From 9th International Conference on Conservative Management of Spinal Deformities - SOSORT 2012 \\ Annual Meeting \\ Milan, Italy. 10-12 May 2012
}

\section{Background}

Self-esteem is defined as a "positive or negative orientation toward oneself" or "a feeling of self-appreciation" (Rosenberg, 1965). In AIS literature, there are contrasting results about the relation between Self-esteem and treatments (Masso et al., 2002; Zhang et al, 2011).

\section{Aim}

Evaluating any correlations between Self-esteem with Health Related Quality of Life (HRQOL) and Body Satisfaction in adolescents with IS.

\section{Methods}

36 Italian and Spanish adolescents with IS (aged 13.1 years; Mean Cobb angle 29 ${ }^{\circ}$; Risser 0 ) were visited for the first time in two different centers (Milan and Barcelona). 14 of them were treated by brace and physiotherapy, 22 only by physiotherapy. Patients answered to Rosenberg self- esteem test, SRS-22, and to Body Satisfaction questionnaires, at the beginning and six months later. Each group was divided into two subgroups, according to the self -esteem scoring: lower values (21-30) and higher values (31-40). Group with low self-esteem was composed of 14 patients, while the other by 22 patients.

\section{Results}

Self-esteem correlated with Body Satisfaction and HRQOL (all its factors) significantly $(\mathrm{p}<0.01)$. Group with high Self Esteem worsened Function $(p=0.003)$ but improved Body Satisfaction ( $\mathrm{p}=0.01)$ in Wilcoxon text. Group of low Self Esteem (79\% treated by physiotherapy) improved Self Image.

\footnotetext{
${ }^{1}$ Fund. Hosp. Univers. Vall D'Hebron. Institut de recerca. Barcelona, Spain
}

Full list of author information is available at the end of the article

\section{Discussions}

Self-esteem correlates with HRQ0L and Body Satisfaction, so that a positive experience of one's own body, and QoL, are associated with higher levels of selfesteem.

Furthermore, Body Satisfaction could be considered a more general construct than Self Image, which belongs to SRS-22 questionnaire. So, people with higher Selfesteem are able to generalize the results of the conservative treatment to all their body, while patients with lower self-esteem, mainly treated by physiotherapy, focused more on Self Image related to their spine and could not appreciate the benefits to the entire body. Future research will aim at increasing sample size for a better understanding of the behaviour of the group of Low self Esteem treated by brace.

\section{Author details}

${ }^{1}$ Fund. Hosp. Univers. Vall D'Hebron. Institut de recerca. Barcelona, Spain. ${ }^{2}$ Research Group of Couple and Family. Ramon LLull University, Barcelona, Spain. ${ }^{3}$ University of Brescia, Brescia, Italy. ${ }^{4}$ RCCS Don Gnocchi, Milan, Italy. 5 Institut Elena Salvá, Barcelona, Spain.

Published: 3 June 2013

\section{References}

1. Cahill S, Mussap AJ: Emotional reactions following exposure to idealized bodies predict unhealthy body change attitudes and behaviors in women and men. J Psychosom Res 2007, 62(6):631-639.

2. Payne WK 3rd, Ogilvie JW, Resnick MD, Kane RL, Transfeldt EE, Blum RW: Does scoliosis have a psychological impact and does gender make a difference? Spine 1997, 22(12):1380-1384.

3. Tones M, Moss N, Polly DW Jr:: A review of quality of life and psychosocial issues in scoliosis. Spine (Phila Pa 1976) 2006, 31(26):3027-3038.

doi:10.1186/1748-7161-8-S1-060

Cite this article as: D'Agata et al.: What is the role of self-esteem in

adolescents with idiopathic scoliosis under a conservative treatment? Scoliosis 2013 8(Suppl 1):060. 